\title{
THE EFFECT OF TRANSPORTATION CHOICES ON ENERGETIC EFFECTIVENES OF RAPESEED PLANTATION
}

\author{
Andrzej WASIAK, Olga ORYNYCZ \\ Bialystok University of Technology, POLAND \\ E-mail of corresponding author: a.wasiak@pb.edu.pl
}

Keywords: biofuels, energetic efficiency, transport of crops

\begin{abstract}
The computer modelling is applied to the analysis of the effect of choices of transportation means, and transport organization on energetic effectiveness of biodiesel production system. In general, needs of transport of harvested crops decreases energetic effectiveness of the production system. Production processes occurring in the whole production system should not consume more energy than the amount that can be obtained in form of final biofuel. Consequently, estimation of the effects caused by various contributing processes, e.g. transportation of biomass between production subsystems, is important for drawing conclusions concerning optimization of the production process.
\end{abstract}

\section{INTRODUCTION}

Biofuels produced out of biomass become important part of liquid fuel industry. They are considered as, at least partial replacement of fossil fuels. It is important that production processes occurring in the whole production system should not consume more energy than the amount that can be obtained in form of final biofuel. Otherwise no gain of energy is achieved. Typical for biofuel production system is coupling between agricultural and industrial subsystems. Moreover, agricultural production is distributed on relatively large area as compared to industrial production. This situation causes needs for transportation of crops between the plantations and industrial processing facility. The present paper presents results of numerical analysis of various choices of transportation means as well as organization of transport with respect to transportation contribution to energetic efficiency of the production system.

Energetic efficiency can be considered as one of the most important characteristics of biofuel production systems, and production processes occurring in that system. Cleveland at al. (1984) have introduced EROEI "Energy Return on Energy Invested" as quantitative measure of energetic efficiency. It was defined as a ratio of energy delivered by some production system to the total energy that have to be consumed in production processes, to deliver the above mentioned amount of energy. Unfortunately, as was indicated by (Murphy at al.2010), various calculation procedures, and several modified definitions are used, causing some ambiguities that have been discussed by Murphy at al. (2011), and also Zhang and Colosi (2013). Recently, the definition that have been introduced by Pickard (2014) was used by the present Authors, in a series of papers: Wasiak and Orynycz, (2014), Wasiak and Orynycz (2015), Orynycz and Wasiak (2014), Wasiak and Orynycz (2015) applying mathematical modelling to estimation of energy efficiency dependence upon several factors determined by methods of production used in agricultural subsystem of rapeseed biodiesel production.

Since biofuel production systems, are usually composed of separated subsystems, having different characteristics, but connected to each other by fluxes of masses or energy, it seems important to establish a way of separate estimation of energetic efficiency of such subsystems, and investigation of subsystem's interactions determining the total energetic efficiency of the production system. It was shown by 
Wasiak and Orynycz (2016) that for a production system the total energy efficiency can be expressed as:

$$
\varepsilon_{\text {tot }}=E_{f u e l} / \Sigma E_{i, j}
$$

where the energy fluxes going into a given i-th subsystem are numbered by index $j$. The partial energetic efficiency of any subsystem can be written as follows:

$$
\varepsilon_{j}=E_{f u e l} / \Sigma E_{i}
$$

It can be easily discovered that the numerator of the expression given by Eq. , and Eq. 2, is the same, while the denominators differ. The numerator is the final amount of energy obtained from the system (delivered out of the system). Consequently, for the case when all partial efficiencies, related to contributing energy expenses in subsystems, are computed as rations to the same value of final energy yield of the whole production system than the energy efficiency of the whole system is expressed by the following rule:

$$
\varepsilon_{t o t}{ }^{-1}=\sum \varepsilon_{j}^{-1}
$$

The same formulas are applicable to the set of technological operations or processes occurring in the production system. It has to be taken into account that all partial, as well as the final, total efficiency should be computed for the same amount of resource. For the case of biofuel production systems, the procedure might refer to particular mass of crops or to particular plantation area, and the same span of time.

The aim of the present paper is to investigate relationships between energetic efficiency of transport between agricultural and industrial subsystems as function of characteristics of transportation means for different plantation sizes. The same dependencies are computed for two cases, namely transportation of rapeseed grain and transportation of raw oil being pressed directly in plantation. Several plantation sizes, as well as several plantation sizes are considered. As characteristics of transportation means the load capacity and fuel consumption are taken into account. The fuel consumption is taken as independent variable varying between different limits specific for the type of vehicle. The data concerning fuel consumption are taken from various catalogues of vehicles as well as publicly available tests, and driver's opinions.

\section{RESULTS AND DISCUSSION}

Numerical computations are performed with the use of a computer program Microcal ORIGIN and data on fuel consumption of various transportation means collected from various sources. Results of computed energetic effectiveness are presented as functions of fuel consumption taken within the limits, reported for particular transportation means (trucks and cisterns). Computations were performed for two cases, namely transport of rapeseed grain or transport of raw oil pressed at the plantation. Grain yield is assumed as $3000 \mathrm{~kg} / \mathrm{ha}$, and correspondingly oil yield is taken as $1100 \mathrm{~kg} / \mathrm{ha}$, and the yield of biodiesel amounts to $380 \mathrm{dm}^{3} / \mathrm{ha}$. The low calorific value of biodiesel fuel is taken as $35 \mathrm{MJ} / \mathrm{dm}^{3}$. The distance that has to be driven between plantation and industrial facility is $100 \mathrm{~km}$. Table I shows the number of vehicles (or courses of one vehicle) needed for transport of grain harvested on various sizes of plantation for several sizes of vehicles. Obviously in the cases of large vehicles and small plantations, the capacity of the vehicle is not utilized in full. 
Table I. Number of vehicles needed for transportation of rapeseed grain between plantation and industrial facility as a function of plantation size, and load capacity of the vehicle.

\begin{tabular}{|c|c|c|c|c|c|c|c|c|c|c|}
\hline \multirow{3}{*}{$\begin{array}{c}\text { Load } \\
\text { capacity } \\
{[\mathrm{kg}]}\end{array}$} & \multicolumn{10}{c|}{ Plantation area [ha] } \\
\cline { 2 - 11 } & 1 & 2 & 3 & 4 & 5 & 6 & 7 & 8 & 9 & 10 \\
\cline { 2 - 11 } & 3000 & 6000 & 9000 & 12000 & 15000 & 18000 & 21000 & 24000 & 27000 & 30000 \\
\hline & \multicolumn{10}{|c|}{ number of vehicles } \\
\hline 2000 & 2 & 3 & 5 & 6 & 8 & 9 & 11 & 12 & 14 & 15 \\
\hline 5000 & 1 & 2 & 2 & 3 & 3 & 4 & 5 & 5 & 6 & 6 \\
\hline 10000 & 1 & 1 & 1 & 2 & 2 & 2 & 3 & 3 & 3 & 3 \\
\hline 20000 & 1 & 1 & 1 & 1 & 1 & 1 & 2 & 2 & 2 & 2 \\
\hline 30000 & 1 & 1 & 1 & 1 & 1 & 1 & 1 & 1 & 1 & 1 \\
\hline
\end{tabular}

An example of results of partial energetic efficiency of transport computed according to Eq. 2, is shown in Fig. 1. The figure presents energetic efficiency of transportation of grain from plantation area 10 hectares

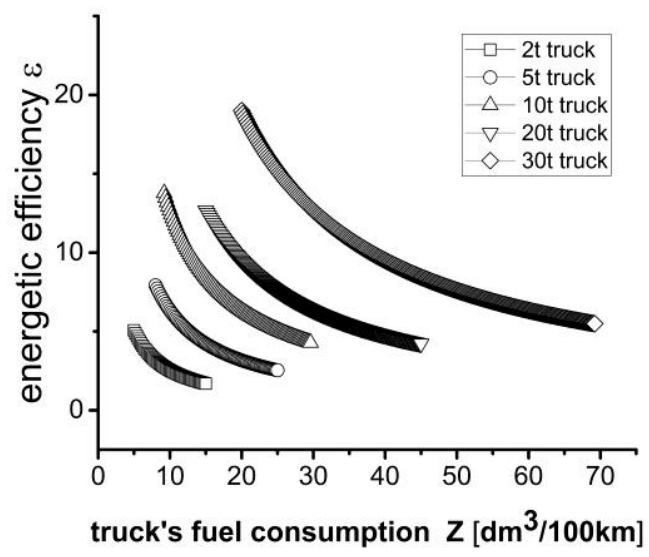

Fig. 1. Energetic efficiency for transportation of rapeseed grain harvested from 10ha field, and crop yield $3000 \mathrm{~kg} / \mathrm{ha}$ by means of trucks of various load capacity.

As it is seen in Fig. 1, in all cases energetic efficiency decreases with an increase of specific fuel consumption, $\left[\mathrm{dm}^{3} / \mathrm{km}\right]$, the character of the dependence is very similar for all types of vehicles. lowest energetic efficiency is observed in the case of smallest vehicle. This result is mostly due to the fact, that the use of small vehicle requires larger number of courses (vehicles). It has to be pointed out, however, that the same value of energetic effectiveness can be reached by different vehicles at different values of fuel consumption. Therefore, in some situations it may be that the use of bigger vehicle offers better efficiency, while in other cases the result might be quite opposite. Consequently, in the practical situations, each case has to be analysed individually.

Fig. 2, in turn, shows similar dependencies for 10 tons truck used for transportation of grain from various sizes of plantation. Again, obviously, the decrease of energetic 
efficiency is observed with an increase of vehicle's fuel consumption. The highest values of energetic efficiency are reachable for small plantation area. This effect is also due to an increase of number of trucks (or courses of one truck) needed to transport whole crop. In this case also the individual choice of the vehicle (its specific fuel consumption) decides on the energetic efficiency of transport operation (since equal energetic efficiencies for different fields can be achieved at different fuel consumption values)

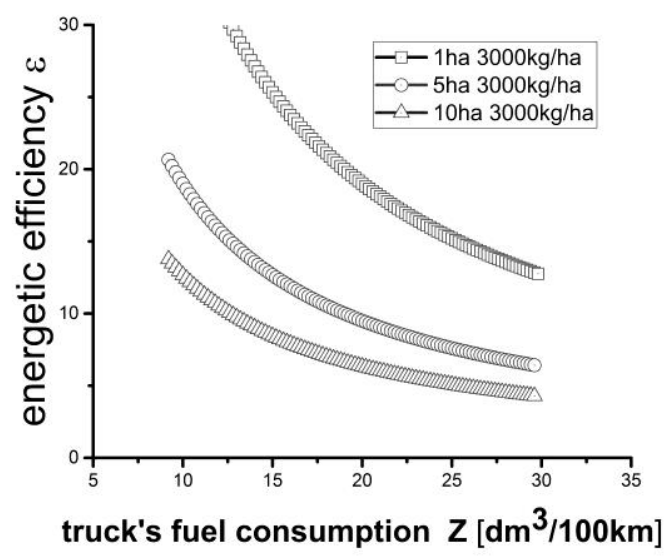

Fig. 2. Energetic efficiency for 10t truck transporting crops from fields differing in area for the crop yield $3000 \mathrm{~kg} / \mathrm{ha}$

An interesting feature can be observed in Fig. 3 showing the dependence of energetic effectiveness of transport as a function of the ratio of mass load capacity, L, of the truck to its specific fuel consumption, Z. As it is seen, a linear relationship for each field size is observed. Energetic efficiency increases with an increase of the ratio $\xi=\mathrm{L} / \mathrm{Z}$.

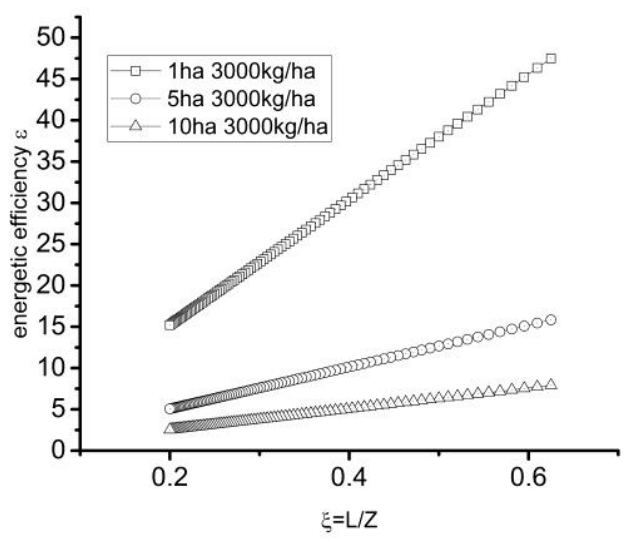

Fig. 3. Energetic efficiency for 10t truck transporting crops from fields differing in area, giving the crop yield $3000 \mathrm{~kg} / \mathrm{ha}$ as function of the ratio of load capacity to fuel consumption.

Similar calculation performed for tor the case of another organization of production processes, i.e. localization of the process of pressing oil at plantation followed by transportation of oil shows the same character of dependencies. An example of results is shown in Fig. 4. 


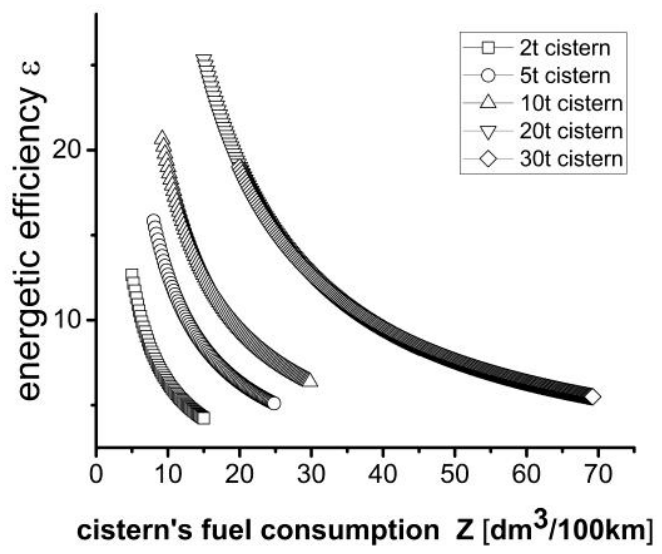

Fig. 4. Energetic efficiency for transportation of rapeseed oil harvested from 5ha field, and crop yield $3000 \mathrm{~kg} / \mathrm{ha}(1100 \mathrm{~kg} / \mathrm{ha}$ of oil)

The dependencies are very similar to those shown in Fig. 1., it seems that at lower fuel consumption limits the energetic efficiency in this case is slightly higher than for the case of grain transportation. Plots for $20 \mathrm{t}$ and $30 \mathrm{t}$ cistern mass capacity practically overlap, what results of the same number of vehicles needed for transportation of oil from plantation of the size chosen.

Direct comparison of energetic efficiency dependencies for both transportation strategies is shown in Fig. 5.

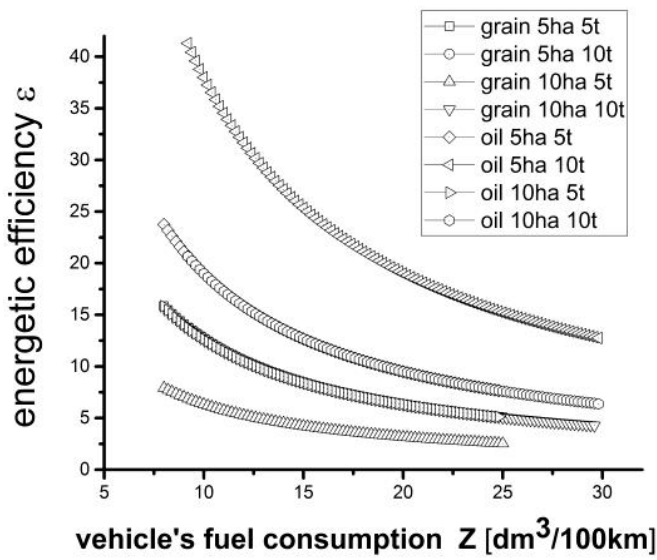

Fig. 5. Comparison of transport energetic efficiency for transportation of rapeseed grain and rapeseed oil harvested from 5 ha, and $10 \mathrm{ha}$ field fields, and crop yield $3000 \mathrm{~kg} / \mathrm{ha}(1100 \mathrm{~kg} / \mathrm{ha}$ of oil) using vehicles of $5 t$ and $10 t$ mass capacity.

For those cases, the highest energetic effectiveness for all values of fuel consumption exhibits the dependence for the case of 10t cistern transporting oil from 5ha field. The curve below is formed by coincidence of the dependencies for oil transport cases: $5 \mathrm{t}$ vehicle - 5ha field, and 10t vehicle -10ha field. The third curve (from the top) results from coincidence of several cases, while the lowest corresponds to the case of transportation of grain grown on 10 ha field by means of truck of $5 \mathrm{t}$ capacity.

Similar linear relationship as shown in Fig. 3 can also be seen in the case of transportation of oil. The slopes of the dependencies obtained by linear regression tend to be larger for oil transport rather than grain. 


\section{CONCLUSIONS}

The energetic effectiveness of transport may strongly contribute to the total energetic effectiveness of rapeseed biodiesel production system. Results of performed model computations show that partial energetic effectiveness of transportation processes depends mainly upon the appropriate choice of the transporting vehicle, especially with respect of its characteristic ratio of load capacity to fuel consumption. Obviously fuel consumption of particular vehicle might depend upon road situation, style of driving, etc. The vehicle also should be correctly chosen with respect of plantation size, and type of crop being transported.

Intuitively, transportation of smaller amount of oil, rather than grain obtained from the same field should lead to better values of energetic effectiveness, it seems however, that incorrect choice of the vehicle might spoil the expected gain in effectiveness. The dependencies of energetic effectiveness upon the ratio of load capacity to fuel consumption suggest that this later characteristic may be the tool for choosing appropriate vehicle. The choice, however, has to be optimized with respect to plantation area (or the amount of the crop that has to be transported.

\section{ACKNOWLEDGMENT}

The research have been performed under financial support from Bialystok University of Technology. Statutory Research Project S/WZ/1/2015.

\section{REFERENCES}

Cleveland, C. J., Costanza, R., Hall, C. A., \& Kaufmann, R. (1984). Energy and the United States economy: a biophysical perspective. Science, 225, p. 890-897.

Murphy, D. J., Hall, C. A. (2011). Energy return on investment, peak oil, and the end of economic growth. Ann. N.Y. Acad. Sci. 1219, p. 52-72.

Murphy, D. J., Hall, C. A. S., Dale, M., \& Cleveland, C. (2011). Order from Chaos: A preliminary protocol for determining the EROEI of fuels. Sustainability, 3, p. 1888-1907.

Orynycz, O., Wasiak, A. (2014). Effects of tillage technology on energetic efficiency of rapeseed plantation for biofuel production. Appl. Computer Sci., 10, p. 67-76.

Pickard, W. F. (2014). Energy Return on Energy Invested (EROI): A quintessential but possibly inadequate metric for sustainability in a solar-powered world?. Proceedings of the IEEE, 102, p. 1118 1122 .

Wasiak, A., Orynycz, O. (2014). Formulation of a model for energetic efficiency of agricultural subsystem of biofuel production. IEEE International Energy Conference, p. 1333-1337.

Wasiak, A., Orynycz, O. (2015). The effects of energy contributions into subsidiary processes on energetic efficiency of biomass plantation supplying biofuel production system. Agriculture and Agricultural Science Procedia, 7, p. 292-300.

Wasiak, A., Orynycz, O. (2015). Effects of field's topology on energetic efficiency of rapeseed plantation for biofuel production. Appl. Computer Sci., 11, p. 83-98.

Zhang, Y., Colosi, L. M. (2013). Practical ambiguities during calculation of energy ratios and their impacts on lifecycle assessment calculations. Energy Policy, 57, p. 630-633. 